\title{
Research
}

Paper

\section{Antifungal activities of a steroid from Pallavicinia lyellii, a liverwort}

\author{
S. Subhisha, A. Subramoniam
}

Tropical Botanic Garden and Research Institute, Pacha-Palode-695562,

Trivandrum District, Kerala. India

Received: 30.4.2005

Revised: 14.7.2005

Accepted: 15.7.2005

Correspondence to:

A. Subramoniam

E-mail:

asubramoniam@yahoo.com

\begin{abstract}
Objective: To determine the in vitro antifungal activity of Pallavicinia /yellii, a liverwort and to obtain clues about the active principle(s) and toxicity, if any.

Materials and Methods: The in vitro antifungal activity of $P$. lyellii was studied against four test fungi (A. niger, A. fumigatus, F. oxysporum and C. albicans) using disc diffusion and direct dilution methods. Water, alcohol, and hexane extracts of $P$. lyellii were tested and the most active alcohol extract was subjected to sequential solvent fractionation. The promising hexane fraction was subjected to thin layer chromatography on silica gel and each spot on the gel was tested for activity and the active spot was chemically analyzed. The alcohol extract was evaluated for its short-term toxicity in mice.

Results: Water, alcohol, and hexane extracts of $P$. lyellii showed varying levels of activity against the test fungi; the alcohol extract exhibited maximum activity. Out of the 4 test fungi, $A$. fumigatus was found to be the most sensitive. The alcohol extract was devoid of conspicuous short-term toxicity to mice. An active hexane fraction was separated from alcohol extract and from this fraction a steroid component with remarkable antifungal activity was isolated using thin layer chromatography (TLC). Conclusion: From P. lyellii a steroidal fraction with remarkable in vitro antifungal activity has been isolated. Further, the extract is devoid of conspicuous toxicity based on short-term toxicity evaluation in mice.
\end{abstract}

KEY WORDS: Antifungal agents, $A$. fumigatus, toxicity.

\section{Introduction}

One of the lower groups of plants with tremendous potential for antifungal drug development is bryophytes. Bryophytes are closely linked with civilization, culture, beliefs, and ethics of humankind. ${ }^{[1]}$ These organisms are also used in the ethnomedical field from times immemorial in many parts of the world. ${ }^{[1,2]}$ Bryophytes are used by different cultural groups for cuts, wounds and skin diseases suggesting that they protect the skin and open wounds from microbial pathogens. ${ }^{|2|}$ Extracts of many bryophytes have been shown to possess varying levels of antibacterial and anticancer activities in vitro ${ }^{[2-5]}$ and many chemical constituents were isolated from bryophytes. ${ }^{[4,6]}$ The bryophytes form an important component of the forest ecosystem in India. ${ }^{[7]}$ A recent exploration yielded about 250 species of bryophytes in Kerala state alone. ${ }^{[8]} \mathrm{Al}-$ though there is ample reason to believe that these plants could contain astonishing antimicrobial compounds, this is largely unexplored against infectious diseases.

A literature search revealed no studies on the antifungal activity of Indian bryophytes. Studies done in other countries indicate that bryophytes are a rich source of antifungal agents.
Cinnamolide from Porella and Makinoa showed activity against a few species of fungal dermatophytes. ${ }^{[2]}$ Lunularin and lunularic acid isolated from Lunularia cruciata showed activity against many species of fungi such as Alternaria brassicola, Botrytis cinera, Septoria nodorum and Uromyces fabae. ${ }^{[2,9]}$ Dumortiera hirsuta, Sphagnum portoricense, and Orthotrichum rupestre were found to be active against Candida albicans. ${ }^{[2,9]}$ Antifungal compounds were isolated from the New Zealand liverwort Plagiochila faciculata. ${ }^{[10,11]}$

Out of several species of liverworts selected on the basis of traditional use or observations and screened for in vitro antifungal activities by the authors, Pallavicinia lyellii showed promising preliminary results. Therefore, a detailed study was carried out on the antifungal activity of this plant.

\section{Materials and Methods}

Plant materials

The bryophyte, Pallavicinia lyellii was collected with its rhizoid, on a sunny day in the month of February, from the forest near Palode, Thiruvananthapuram District, Kerala State. The plants were identified by a bryophyte taxonomist of TBGRI and voucher specimens were preserved. 


\section{Chemicals and reagents}

Agar, dextrose, and dimethyl sulfoxide (DMSO) were from Sigma chemicals Co. St. Louis MO. All other chemicals used were of analytical grade purchased from E. Merk India Ltd. Mumbai and SRL, India.

\section{Preparation of water extract}

The plant thalli with rhizoids were dried, powdered, and extracted with distilled water $(5 \mathrm{~g} / 100 \mathrm{ml})$ with constant stirring for $4 \mathrm{~h}$ and then filtered through a filter paper. Residue was again extracted as above with water. The combined filtrate was freeze-dried in a lyophilizer. The yield of the water extract was determined $^{[12]}$ (Since the heat sensitivity of the extract with reference to bioactivity is not known, the extraction was carried out at a low temperature without using rigorous extraction procedures).

\section{Alcohol extract}

The alcohol extract of the powder of $P$. lyellii was prepared similarly using ethyl alcohol instead of distilled water. However, in this case the combined extract was evaporated to dryness in a rotary evaporator under reduced pressure at $40{ }^{\circ} \mathrm{C}$, as described elsewhere. ${ }^{[12]}$ The yield of the alcohol extract was determined.

\section{Hexane extract}

The hexane extracts of the powder was prepared as above using n-hexane instead of alcohol. However, to ensure complete extraction $2 \mathrm{~g}$ powder was extracted with $100 \mathrm{ml}$ hexane and the process was repeated 3 times. The filtrates from the extractions were mixed and dried in a rotary evaporator under reduced pressure at $40{ }^{\circ} \mathrm{C}$. The yield of the extract was determined.

\section{Assay for antifungal activities}

Test fungi were obtained from the Institute of Microbial Technology, Chandigarh, India. In vitro antifungal activity was tested against 4 fungi: Candida albicans (Robin) Berkhout [MTCC 227], Aspergillus niger Tieghem [MTCC 1344], Aspergillus fumigatus Fres [MTCC 343], and Fusarium oxysporum Schlecht [MTCC 284]. Stock cultures were maintained in Sabouraud agar. Inoculum for Candida albicans was prepared by spread plating $0.2 \mathrm{ml}$ of $24 \mathrm{~h}$ old cultures grown in Sabouraud broth. For Aspergillus niger and A. fumigatus, dried spores were distributed uniformly on the surface of agar plates with the help of a sterile cotton swab. Fusarium oxysporum was inoculated by taking a piece of fungal colony on a sterile cotton swab and gently swabbing on the surface uniformly.

Sabouraud (maltose) Agar (HI-MEDIA) was used as the medium for the antifungal assay by the disc diffusion method. Spread plates were prepared with the proper concentration of inocula. A known concentration of the extract in Tris - buffer (for water extract) or in 10\% DMSO - Tris buffer (for alcohol extract) $(40 \mu \mathrm{l})$ was added on each disc. Amphotericin B (Sigma), $0.25 \mathrm{mg} / \mathrm{ml}$, and ketoconazole were used as a positive control and DMSO-Tris buffer (1:9) as a negative control for alcohol extract and only Tris-buffer was used for water ex- tract. After $48-72 \mathrm{~h}$ of incubation at $27-28{ }^{\circ} \mathrm{C}$, the inhibition zones from the centre of the disc to the inner margin of the surrounding fungal growth was measured in millimeters and recorded.

\section{Assay for antibacterial activities}

In vitro antibacterial activity was tested against Escherichia coli and Staphylococcus aureus by the agar overlay method. ${ }^{[13]}$

\section{Chemical analysis of the active extract}

The most active alcohol extract was subjected to solvent fractionation by sequential extraction with n-hexane, chloroform, ethyl acetate, butanol, and water. Each fraction was tested for antifungal activity. The most active hexane fraction was subjected to chemical analysis to determine the classes of compounds present in it. ${ }^{14]}$ The presence of alkaloids (Dragendorff reagent and Mayer's reagent), coumarins (Borntagrs reaction), flavanoids (Shinoda test), steroids (Lieberman Burchard test), steroids and terpenes (vanillinsulphuric acid reagent) were analyzed. The fraction was subjected to silica gel Thin Layer Chromatography (TLC) using chloroform as a solvent. The chromatograms were sprayed with various reagents to detect the presence of various classes of compounds. It is also exposed to UV fluorescence and inspected. ${ }^{[14]}$ Each spot in preparative TLC was identified on the basis of relative mobility and scrapped off; and eluted with alcohol and tested for antifungal activity using disc diffusion method.

\section{Toxicity evaluation in mice}

To study the short-term toxicity, three groups of male mice (20-25 g, body weight) each consisting of six mice were used. Group I served as control (received water), while groups II and III received 250 , and $500 \mathrm{mg} / \mathrm{kg}$ of alcohol extract respectively. The drug was administered daily for 15 days (p.o).

The behavior of the animals was observed daily for $1 \mathrm{~h}$ in the forenoon (10 to 11 A.M) for 14 days. The behavioral parameters observed were convulsion, grooming, hyperactivity, sedation, loss of righting reflex, and increased respiration. Initial and final body weights, water and food in take, and state of stool were observed. Rectal temperature was also recorded. The animals were killed on the fifteenth day. Hematological and serum biochemical parameters were determined. Liver, kidneys, spleen, and heart were dissected out, and weighed and observed for morphological and pathological changes. Hemoglobin was measured using hemoglobinometer with comparison standards. Glutamate pyruvate transaminase (GPT) and glutamate oxaloacetate transaminase (GOT) were measured by the method of Reitman and Frankel ${ }^{[15]}$ and alkaline phosphatase by determining hydrolyzed phenol with antipyrine. ${ }^{[16]}$ The peritoneal macrophage and total leucocyte count were done. ${ }^{[17]}$

\section{Statistical analysis}

Statistical comparison was done using one-way analysis of variance (ANOVA) and Dunnett's test for the data on toxicity studies. $\mathrm{P}<0.05$ was considered significant. 


\section{Results}

The antifungal activity of different extracts of $P$. lyellii against $A$. niger, $A$. fumigatus, $F$. oxysporum, and $C$. albicans are given in Table 1. Although all the extracts showed varying levels of activity against all the test fungi, the alcohol extract was found to be more active than water and hexane extracts. Out of the four test fungi, $A$. fumigatus was found to be more susceptible. The growth of this organism was inhibited at a concentration as low as $80 \mathrm{ng} /$ disc of alcohol extract, whereas the growth of $F$. oxysporum, $A$. niger, and $C$. albicans was inhibited at 10, 50 and $100 \mu \mathrm{g} /$ disc, respectively (Table 1 and $3)$.
The inhibition of growth of $A$. fumigatus by the alcohol extract was confirmed by directly adding into the liquid medium. As shown in Table 2, the growth inhibition was observed over a wide range of concentrations. The mycelia growth was inhibited more than $50 \%$ at $1 \mu \mathrm{g} / \mathrm{ml}$; the inhibition was almost complete at $1 \mathrm{mg} / \mathrm{ml}$ level. Thus, it was found to be more potent than the commonly used antifungal agent, ketoconazole, which showed $82 \%$ growth inhibition at $1 \mathrm{mg} / \mathrm{ml}$.

In contrast to the antifungal activity, the extract showed very marginal antibacterial activity. In the case of E. coli, the extract showed significant inhibition zone in the disc diffusion assay at $250 \mu \mathrm{g}$ /disc, while $S$. aureus was found to be resist-

Table 1

Antifungal activities of $P$. lyellii extracts

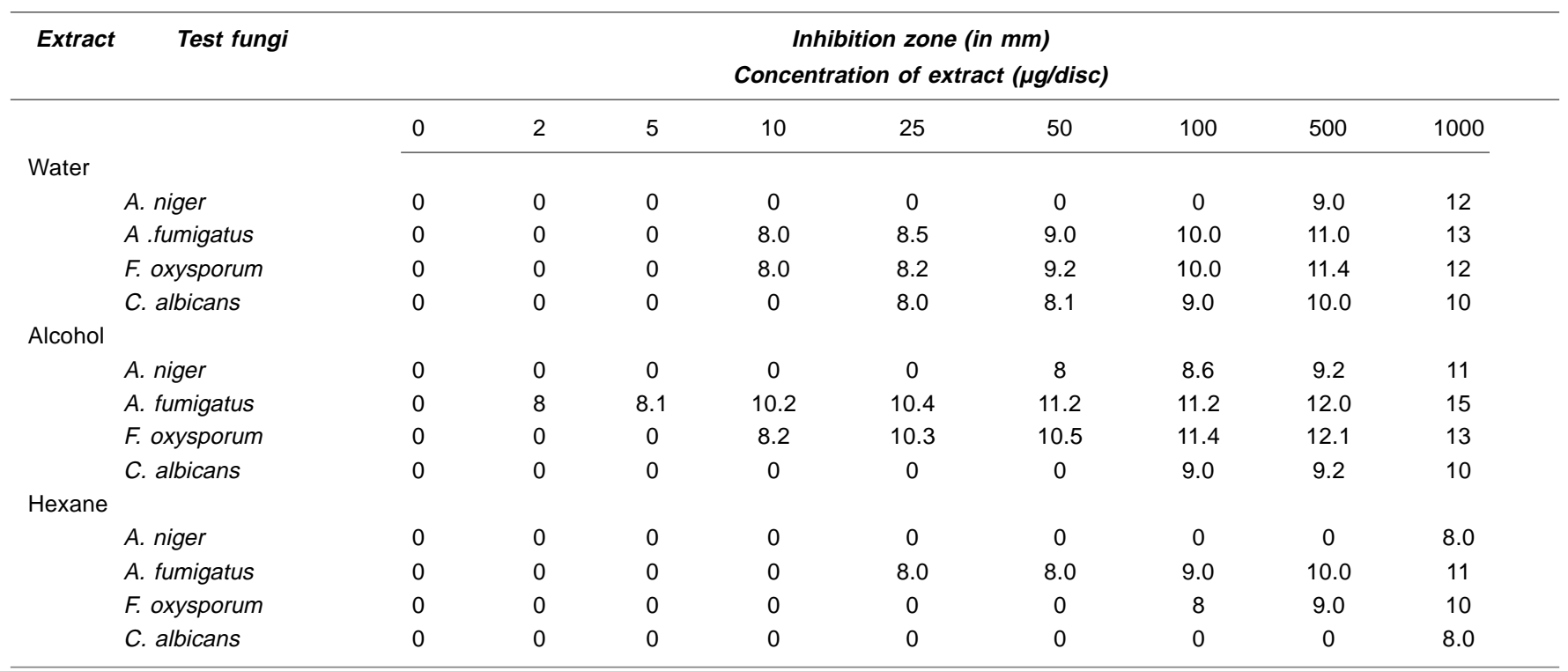

Values are mean \pm SD. $n=3$ in each group. The antifungal activity was assayed by disc diffusion method; $40 \mu \mathrm{l} / \mathrm{disc}$ (diameter of disc was $6 \mathrm{~mm})$. Amphotericin $\mathrm{B}$ (100 $\mu \mathrm{g} /$ disc) was used as a positive control.

Table 2

Antifungal activity of $P$. lyellii (alcohol extract) against $\boldsymbol{A}$. fumigatus

\begin{tabular}{cc}
\hline $\begin{array}{c}\text { Concentration of extract } \\
(\mathbf{m g} / \boldsymbol{m} \mathbf{l})\end{array}$ & $\begin{array}{c}\text { Mycelial weight } \\
\text { (in } \mathbf{~} \boldsymbol{g})\end{array}$ \\
\hline 0 (Control) & $66 \pm 3(0)$ \\
0.001 & $29 \pm 2(56)$ \\
0.01 & $17 \pm 2(74)$ \\
0.1 & $6 \pm 1(91)$ \\
1.0 & $1 \pm 0(99)$ \\
Ketoconazole (1.0) & $11 \pm 2(82)$ \\
\hline
\end{tabular}

The extract was directly added into the liquid medium. Values are mean \pm SD of 3 different experiments, (corrected to nearest whole number). Values in brackets represent \% growth inhibition.
Table 3

Anti $A$. fumigatus activity guided isolation of a steroidal fraction from $P$. lyellii

\begin{tabular}{lccccc}
\hline & \multicolumn{5}{c}{$\begin{array}{c}\text { Inhibition zone (in mm) } \\
\text { Concentraction of extract (ng/disc) }\end{array}$} \\
\hline & Control (0) & 10 & 40 & 80 & 100 \\
\cline { 2 - 6 } & 0 & 0 & 0 & 9 & 11 \\
$\begin{array}{l}\text { Alcohol extract } \\
\text { from } P \text {. lyelli }\end{array}$ & & & & & \\
$\begin{array}{l}\text { Hexane fraction from } \\
\text { the alcohol extract }\end{array}$ & 0 & 0 & 8 & 9 & 10 \\
$\begin{array}{l}\text { Water fraction from } \\
\text { the alcoholextract } \\
\begin{array}{l}\text { Steroid isolate from } \\
\text { the hexane fraction }\end{array}\end{array}$ & 0 & 0 & 0 & 0 & 10 \\
\hline
\end{tabular}

Values are mean $\pm S D, n=3$. The activity was assayed by disc diffusion method. 
Table 4

Antibacterial activities of $P$. lyellii extracts

\begin{tabular}{llccccccc}
\hline Extract & Test bacteria & \multicolumn{7}{c}{ Inhibition zone (in mm) } \\
\hline \multirow{4}{*}{ Water } & & \multicolumn{4}{c}{ Concentration of extract $(\mathbf{m g}$ /disc) } \\
& Control (0) & 0.1 & 0.25 & 0.5 & 1 & 2 & 5 \\
\cline { 3 - 9 } Alcohol & E. coli & 0 & 0 & 0 & 9 & 9 & 10 & 10 \\
& S. aureus & 0 & 0 & 0 & 0 & 0 & 0 & 0 \\
& E. coli & 0 & 0 & 8 & 9 & 10 & 11 & 12 \\
& S. aureus & 0 & 0 & 0 & 0 & 0 & 0 & 0 \\
& E. coli & 0 & 0 & 0 & 0 & 0 & 0 & 0 \\
& S. aureus & 0 & 0 & 0 & 0 & 0 & 0 & 0
\end{tabular}

Values are mean $\pm S D . n=3$ in each group. The antibacterial activity was assayed by disc diffusion method.

ant to this extract even at a high concentration of $10 \mathrm{mg} /$ disc (Table 4). When the alcohol extract was further fractionated by sequential solvent extraction, the activity was found in the hexane and water fractions (Table 3). In the case of the hexane fraction of alcohol extract, concentration that was required for measurable inhibition of $A$. fumigatus growth in the disc diffusion assay was approximately $40 \mathrm{ng} /$ disc as against 80 $\mathrm{ng} /$ disc $(2.0 \mu \mathrm{g} / \mathrm{ml} ; 40 \mu \mathrm{l} /$ disc) of the original alcohol extract. The yield of the ethanol extract was $7.5 \%$ of the dry plant powder, while the yield of the hexane fraction was $65 \%$ of the extract. The chloroform, ethyl acetate, and butanol fractions were inactive even at $100 \mathrm{ng} /$ disc level, while water fraction showed activity at $100 \mathrm{ng} /$ disc. The yield of this water fraction is only $7 \%$ of alcohol extract. Upon chemical analysis, the water fraction showed the presence of coumarins.

When the hexane extract was subjected to TLC separation on silica gel using different solvent systems [hexane-ethyl acetate (1:1), chloroform-methanol (8:2) and chloroform], the solvent chloroform was found to give better separation (Figure 1). The extract was resolved into several spots. The chromatograms were sprayed with different reagents or exposed to UV and inspected. ${ }^{[14]}$ Each spot in preparative TLC was identified on the basis of relative mobility, and scrapped off and eluted with chloroform and tested for anti $A$. fumigatus activity using disc diffusion method. The fast moving dominant band/spot was found to be very active. This isolate showed activity at $10 \mathrm{ng} /$ disc. As judged from Lieberman's reaction,
Figure 1: Thin layer chromatographic separation of hexane fraction from $P$. lyellii on silica gel $\mathrm{G}$ using chloroform as a solvent. 1, Active fast moving spot identified as a steroid.

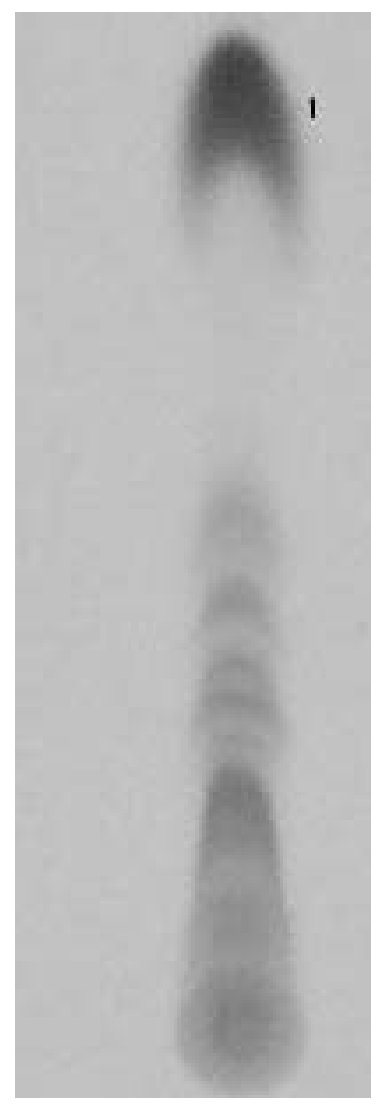

this isolate was a steroid (Figure 1). The yield of the steroid isolate was $34 \%$ of the hexane fraction.

In short-term toxicity evaluation, none of the parameters studied was influenced by the alcohol extract administration for 15 days except serum triglyceride level which was significantly decreased at the high dose $(500 \mathrm{mg} / \mathrm{kg})$ (Table 5).

\section{Discussion}

This study reports for the fist time the potent antifungal activity of $P$. lyellii. The active fraction obtained from this

Table 5

Effect of alcohol extract of $P$. lyelli administration for 15 days to mice on serum biochemical parameters

\begin{tabular}{|c|c|c|c|c|c|c|c|c|}
\hline Groups & & $\begin{array}{l}\text { Glucose } \\
\text { (mg/dl) }\end{array}$ & $\begin{array}{l}\text { SGOT } \\
\text { (IU/I) }\end{array}$ & $\begin{array}{l}\text { SGPT } \\
(I U / I)\end{array}$ & $\begin{array}{c}\text { Urea } \\
\text { (mg/dl) }\end{array}$ & $\begin{array}{c}\text { Total protein } \\
(g / d l)\end{array}$ & $\begin{array}{c}\text { Total cholesterol } \\
\text { (mg/dl) }\end{array}$ & $\begin{array}{c}\text { Triglycerides } \\
\text { (mg/dl) }\end{array}$ \\
\hline Control & & $112 \pm 3$ & $70 \pm 5.6$ & $26 \pm 2.8$ & $33 \pm 1.4$ & $6.3 \pm 0.6$ & $140 \pm 7$ & $141 \pm 4$ \\
\hline $250 \mathrm{mg} / \mathrm{kg}$ & & $108 \pm 6$ & $71 \pm 6.0$ & $26 \pm 2.1$ & $31 \pm 1.8$ & $6.8 \pm 0.8$ & $136 \pm 9$ & $138 \pm 5$ \\
\hline $500 \mathrm{mg} / \mathrm{kg}$ & & $113 \pm 8$ & $68 \pm 7.2$ & $27 \pm 2.0$ & $29 \pm 1.5$ & $7.6 \pm 0.4$ & $143 \pm 8$ & $111 \pm 4^{*}$ \\
\hline One-way & $F$ & 1.02 & 0.61 & 0.41 & 0.82 & 1.22 & 0.93 & 23.44 \\
\hline
\end{tabular}

Values are mean $\pm S D, n=6$ in each group. $d f=2,15 ;{ }^{*} P>0.001$ compared to control (Dunnett's test). 
liverwort showed varying levels of activity against all the four test fungi. This suggests that it has a broad spectrum of activity, although the degree of susceptibility could differ between different organisms. There is a need to test the in vivo activity of the extract apart from the effect on many other fungi. It is of interest to note that the plant extract appears to be nontoxic as judged from the general short-term toxicity study in mice.

The limited studies clearly indicate that the active principle is a steroid. Further studies are under progress in this laboratory to characterize the active principle and the mechanism of action. The drug inhibits the germination of the spore, as well as the multiplication of mycelia. The active principle, being a lipophilic steroid is likely to act intracellularly.

$P$. lyellii can be easily obtained through cultivation. The plant material appears to be an attractive material for antifungal drug development. There is an urgent need to develop new antifungal agents. Almost all of the antifungal agents, which are currently in use are relatively expensive and have toxic side effects. ${ }^{[18]}$

\section{Acknowledgments}

The authors acknowledge Dr. G.M. Nair, Director, Tropical Botanic Garden and Research Institute (TBGRI), and late Dr. G. Sreekandan Nair, former Director, TBGRI for their keen interest and encouragement in the course of this research work. Dr. C.K.C.S. Pillai, Professor of Botany (retired), MSM College, Kayamkulam, Kerala State, Dr. P.V. Madhusoodanan, Professor of Botany, University of Calicut and CN Manju, Research Scholar, University of Calicut are gratefully acknowledged for their help in the identification of the plant species. The authors express their sincere thanks to Mr. G. Santhoskumar, Animal House Technician, for providing technical assistance in the execution of animal experiments.

\section{References}

1. Pant G, Tewari SD. Bryophytes and mankind. Ethnobotany 1990; 2:97-103.

2. Subramoniam A, Subhisha S. Bryophytes of India: A potential source of anti- microbial agents. In: Khan IA, Khanum A, editors. Role of biotechnology in medicinal and aromatic plants. Vol.11. Hyderabad, India: Ukaaz Publications; 2005.

3. Ando H, Matsua A. Applied Bryology. In: Schultze-Motel W, editor. Advances in Bryology. Vol. 2. J Cramer. Germany: Vaduz; 1984.

4. Adio AM, Paul C, Kloth P, Konig WA. Sesquiterpenes of the liverwort, Scapania undulata. Phytochemistry 2004;65:199-206.

5. Subramoniam A, Subhisha S, Ajikumaran Nair S, Shylesh BS, Nair GM. Bryophytes of Kerala: A potential source of anti-cancer agents. Amla Res Bull 2003:23:78-83.

6. Asakawa Y, Heidelberger M. Chemical Constituents of the Hepaticae. Progress in the Chemistry of Organic Natural Products Bd. 42. Wien - New York: Springer; 1982.

7. Srinivasan C. Distribution of Hepaticae and Anthocerotae in India. In: Chopra RN, editor. Topics in Bryology. New Delhi: Allied Publishers Ltd; 1998.

8. Manju CN, Madhusoodanan PV. Studies on the bryophyte flora of Kerala (South India): An introduction. J Econ Taxon Bot 2002;26:697-706.

9. McCleary A, Walkington DL. Mosses and antibiosis. Rev Bryol Lichnol 1966; 34:309-17.

10. Lorimer SD, Perry NB. An antifungal bibenzyl from the New Zealand liverwort, Plagiochila stevensoniana. J Nat Prod 1993;56:1444-50.

11. Lorimer SD, Perry NB. Antifungal Hydroxy acetophenones from the New Zealand liverwort, Plagiochila fasciculata. Planta Medica1994;60:386-7.

12. Subramoniam A, Evans DA, Rajasekharan S, Pushpangadan P. Hepatoprotective activity of Trichopus zeylanicus extract against paracetamol induced hepatic damage in rats. Indian J Exp Biol 1998;36:385-9.

13. Murray PR, Baron EJ, Pfaller MA, Tenover FC, Yolke RH. Manual of Clinical Microbiology, $6^{\text {th }}$ ed. London: Mosby Year Book; 1995.

14. Wagner H, Bladt S, Zgainski EM. Plant drug analysis. Berlin, Heidelberg, New York, Tokyo: Springer- Verlag; 1984.

15. Reitman S, Frankel S. Colorimetric method for the determination of serum glutamate oxalo-acetate and glutamae pyruvate transaminase. Am J Clin Pathol 1957;28:56-63.

16. Kind PRN, King EJ. Estimation of plasma phosphatases by determination of hydrolyzed phenol with antipyrine. J Clin Pathol 1954;70:322-30.

17. Subramoniam A, Rajasekharan S, Latha PG, Evans DA, Pushpangadan P. Immunomodulatory and anti-tumor activities of Janakia arayalpathra. Fitoterapia 1996;57:140-4.

18. Morens DM., Folkers GK, Fauci AS. The challenges of emerging and re- emerging infectious diseases. Nature 2004;430:242-9.

\title{
INTERNATIONAL CONFERENCE ON CLINICAL RESEARCH
}

\author{
Theme : "India's Emergence as Hub for Clinical Research" \\ Date : December $3^{\text {rd }}-4^{\text {th }}, 2005$ \\ Venue : Auditorium, Indian National Science Academy, \\ Bahadurshah Safar Marg, New Delhi - 110002.
}

\section{Contact:}

\author{
Dr. S.K. GUPTA \\ Institute of Clinical Research (India) \\ D-41 Defence Colony, New Delhi-110 024. \\ E-mail: skgupta@icriindia.com; Website: www.icriindia.com
}

